Published in final edited form as:

Am J Perinatol. 2015 February ; 32(3): 225-232. doi:10.1055/s-0034-1382255.

\title{
Inhaled Nitric Oxide Increases Urinary Nitric Oxide Metabolites and Cyclic Guanosine Monophosphate in Premature Infants: Relationship to Pulmonary Outcome
}

\author{
Philip L. Ballard, MD, PhD1, Roberta L. Keller, MD¹, Dennis M. Black, PhD², David J. \\ Durand, MD $^{3}$, Jeffrey D. Merrill, MD $^{3}$, Eric C. Eichenwald, MD ${ }^{4}$, William E. Truog, MD $^{5}$, Mark \\ C. Mammel, MD ${ }^{6}$, Robin Steinhorn, MD ${ }^{7}$, Rita M. Ryan, MD $^{8}$, Sherry E. Courtney, MD $^{9}$, Hart \\ Horneman, BS ${ }^{1}$, Roberta A. Ballard, MD ${ }^{1}$, and Investigators of TOLSURF Pilot and \\ TOLSURF \\ ${ }^{1}$ Department of Pediatrics, University of California, San Francisco, California \\ ${ }^{2}$ Department of Epidemiology and Biostatistics, University of California, San Francisco, California \\ ${ }^{3}$ Division of Neonatology, Children's Hospital and Research Center Oakland, Oakland, California \\ ${ }^{4}$ Department of Pediatrics, University of Texas Medical School, Houston, Texas \\ ${ }^{5}$ Department of Pediatrics, Children's Mercy Hospitals and Clinics, University of Missouri-Kansas \\ City School of Medicine, Kansas City, Missouri \\ ${ }^{6}$ Department of Pediatrics, Children's Hospital and Clinics of Minnesota, St. Paul, Minnesota \\ ${ }^{7}$ Department of Pediatrics, University of California Davis Children's Hospital, Sacramento, \\ California \\ ${ }^{8}$ Department of Pediatrics, Medical University of South Carolina, Charleston, South Carolina \\ ${ }^{9}$ Department of Pediatrics, University of Arkansas for Medical Sciences, Little Rock, Arkansas
}

\begin{abstract}
Objective-Inhaled nitric oxide (iNO) has been tested to prevent bronchopulmonary dysplasia (BPD) in premature infants, however, the role of cyclic guanosine monophosphate (cGMP) is not known. We hypothesized that levels of NO metabolites (NOx) and cGMP in urine, as a
\end{abstract}

\footnotetext{
Address for correspondence Philip L. Ballard, MD, PhD, Suite 150, 3333 California St, San Francisco, CA 94118, (ballardp@peds.ucsf.edu).

Note

Other contributing TOLSURF Pilot and TOLSURF investigators: Elizabeth Rogers, MD (University of California San Francisco, San Francisco CA); Anne Marie Reynolds, MD (Women and Children's Hospital of Buffalo, Buffalo, NY); Aruna Parekh, MD (Stonybrook University Hospital, Stonybrook, NY); Dennis Mayock, MD (University of Washington, Seattle, WA); Mark Hudak, MD (University of Florida College of Medicine at Jacksonville, UF Health and Wolfson Children's Hospital, Jacksonville, FL); Beatrice Stefanescu, MD, Jennifer B. Helderman, MD, T. Michael O'Shea, MD (Wake Forest School of Medicine and Forsyth Medical Center, Winston Salem, NC); Michael Georgieff, MD, Catherine M. Bendel, MD (University of Minnesota Amplatz Children's Hospital, Minneapolis, MN); Andrea Lampland, MD (Department of Pediatrics, Children's Hospital and Clinics of Minnesota, St. Paul, MN); Ellen Bendel-Stenzel, MD, Neil Mulrooney (Children's Hospitals and Clinics of Minnesota, Minneapolis, MN); Frances Koch, MD (Medical University of South Carolina, Charleston, SC); Reddy Dhanireddy, MD (University of Tennessee-Memphis, Memphis TN); Victor McKay, MD (All Children's Hospital, St Petersburg, FL); Rajan Wadhawan, MD (Florida Hospital for Children, Orlando FL); Nicolas Porta, MD (Northwestern Memorial Hospital, Chicago, IL)
} 
noninvasive source for biospecimen collection, would reflect the dose of iNO and relate to pulmonary outcome.

Study Design-Studies were performed on 125 infants who required mechanical ventilation at 7 to 14 days and received 24 days of iNO at 20-2 ppm. A control group of 19 infants did not receive iNO.

Results-In NO-treated infants there was a dose-dependent increase of both NOx and cGMP per creatinine (maximal 3.1- and 2-fold, respectively, at 10-20 ppm iNO) compared with off iNO. NOx and cGMP concentrations at both 2 ppm and off iNO were inversely related to severity of lung disease during the 1st month, and the NOx levels were lower in infants who died or developed BPD at term. NOx was higher in Caucasian compared with other infants at all iNO doses.

Conclusion-Urinary NOx and cGMP are biomarkers of endogenous NO production and lung uptake of iNO, and some levels reflect the severity of lung disease. These results support a role of the NO-cGMP pathway in lung development.

\section{Keywords}

nitric oxide; cyclic GMP; bronchopulmonary dysplasia; premature; urine

Inhaled nitric oxide (iNO) is currently used in infants, children, and adults as treatment for pulmonary hypertension, exploiting the selective and potent vasodilation properties of iNO that are mediated through activation of soluble guanylate cyclase to produce the secondary messenger cyclic guanosine monophosphate (cGMP). NO also promotes formation of nitrosylated proteins that act independent of cGMP to affect protein structure, location, and function including transcriptional activity. ${ }^{1}$

iNO has been used in clinical trials with premature infants for prevention of bronchopulmonary dysplasia (BPD) and later pulmonary morbidity. The hypothesis underlying this therapy is that iNO corrects a developmental deficiency of endogenous NO production in premature infants and promotes alveogenesis in the injured, immature lung. Benefit from iNO has been observed in some studies, but not in others, which may reflect the dosing regimen and/or racial/ethnic composition of the study group. ${ }^{2}$ Other possible factors in efficacy may be individual variability related to delivery of iNO to the lung periphery, rate of metabolism of NO, or maturity/efficiency of cGMP formation.

Animal studies support a role for NO in lung development. Epithelial and neuronal NO synthase (NOS) are present in lung epithelium of fetal baboons, and both NOS activity and plasma nitrate increase in the third trimester. ${ }^{3,4}$ Infant baboons delivered prematurely are deficient in endogenous NO production, and NOS activity remains suppressed after premature birth. ${ }^{5}$ iNO treatment of these animals increased lung weight and volume, enhanced cell proliferation, and normalized elastin deposition. ${ }^{6}$ In infant rats, downregulation of vascular endothelial growth factor (VEGF) decreased NO production and delayed lung growth and alveolar development; these parameters were restored with iNO treatment. ${ }^{7}$ Using the bleomycin model of lung disease, iNO treatment improved alveolization following lung injury in infant rats. ${ }^{8}$ Prematurely delivered lambs have 
diminished levels of endothelial NOS and soluble guanylate cyclase plus findings of reduced alveolar growth and increased respiratory tract resistance, which are preserved with prolonged iNO treatment. ${ }^{9-11}$

Because NO is rapidly metabolized in the lung and circulation, measurement of NO metabolites (NOx), which include nitrate, nitrite, and nitrosylated compounds, has been used as a surrogate marker of NO production/content. Previously, we reported that iNO treatment at 2-20 ppm in premature infants with lung disease results in a dose-dependent increase in NOx concentrations in plasma and tracheal aspirate. ${ }^{12}$ Increases in plasma NOx are also reported for infants with pulmonary hypertension who received iNO. ${ }^{13,14}$ While these findings document delivery and uptake of $\mathrm{NO}$ in lungs of iNO-treated infants, there is currently no information on whether levels of cGMP change with iNO as an indication of stimulated activity of soluble guanylate cyclase in lung cells.

In the current study, we hypothesized that levels of NOx and cGMP in urine, as a noninvasive source for biospecimen collection, would reflect the dose of iNO to premature infants and relate to pulmonary outcome near term. We describe an iNO dose-dependent relationship for both NOx and cGMP levels in urine and significant influences of race/ ethnicity and severity of lung disease on urinary NOx.

\section{Methods}

\section{Patient Populations}

Studies of iNO effects were performed on a subpopulation of infants with urine samples from the multicenter Trial of Late Surfactant to Prevent BPD (TOLSURF, 89 infants from 19 clinical sites) and the TOLSURF Pilot (36 infants from 8 clinical sites). Both trials enrolled premature infants who required mechanical ventilation at 7 to 14 days postnatal age. All infants received iNO by the dose regimen of the nitric oxide chronic lung disease (NO CLD) Trial ${ }^{15}$ beginning at enrollment and were randomized to receive either Infasurf or sham therapy. Results of TOLSURF Pilot have been published ${ }^{16}$ and data collection and analysis of TOLSURF is ongoing. Premature infants enrolled in the Prematurity and Respiratory Outcome Program, who did not receive iNO, were a control cohort (19 infants from three TOLSURF sites); this study enrolled all infants of $<29$ weeks' gestation and $<7$ days of age without regard to respiratory status. Extensive clinical data were obtained in all three studies. Race/ethnicity was self-reported per National Institutes of Health (NIH) guidelines. Severity of early lung disease was measured using the Respiratory Severity Score (RSS), which is defined as fraction of inspired oxygen $\left(\mathrm{Fio}_{2}\right) \times$ mean airway pressure in intubated infants; for nonintubated infants with nasal cannula, RSS was calculated as $\mathrm{Fio}_{2} \times$ liters per minute flow rate. Pulmonary outcome was assessed at both 36 and 40 weeks postmenstrual age (PMA) using a room air challenge for infants in supplemental oxygen $<0.30^{17}$; BPD (moderate/severe) was diagnosed for infants on assisted ventilation, $>0.30$ oxygen, on nasal cannula at $>4 \mathrm{~L} / \mathrm{min}$ in room air or any flow rate with oxygen, and failing the room air challenge. Each of the studies was approved by Institutional Review Boards (IRBs) of participating institutions and required informed consent by the parents. 


\section{Urine Collection and Assays}

Infant urine samples were collected by placing cotton balls in the diaper for 4 to 8 hours and then extruding the urine using a syringe; samples were stored at $-80^{\circ} \mathrm{C}$. NOx were assayed as previously described, ${ }^{12}$ using vanadium reduction and a Sievers Nitric Oxide Analyzer (GE Water \& Power, Boulder, CO). cGMP and creatinine were assayed using commercial ELISA kits (Cayman Chemical Co., Ann Arbor, MI). Results for NOx (nmol) and cGMP (pmol) were normalized to creatinine $(\mu \mathrm{g})$ to adjust for renal excretory function. Because urine is collected from infants over several hours, we tested the effect of incubating urine at $37^{\circ} \mathrm{C}$ for 3 hours before assay; there was no effect of incubation on NOx, cGMP, or creatinine values. Samples with $>20 \%$ variability of duplicates were re-assayed.

\section{Data Analysis}

In our analyses we used only data obtained $\geq 24$ hours after a change in dose of iNO. Data with normalized distribution are expressed as mean \pm standard deviation or standard error and were analyzed by Student $t$-test and ANOVA for multiple comparisons; skewed data are expressed as the median value and were analyzed by the Wilcoxon rank-sum test. Timecourse and dose-response data were examined by linear regression. Analysis of quartile distribution of NOx data and pulmonary outcome was made using the two-sample test for equality of proportions with continuity correction.

\section{Results}

Studies were performed on urine samples from 125 premature infants who received iNO in the TOLSURF and TOLSURF Pilot trials and 19 premature infants not receiving iNO (control). The two groups were similar with regard to gestational age (range 23-29 weeks) and gender distribution, however, control infants had higher birth weight and less severe lung disease, as reflected by RSS and incidence of BPD at 36 weeks PMA, consistent with different enrollment criteria in the two studies (Table 1).

\section{Control Infants}

Fig. 1 presents data for urinary NOx, cGMP, and cGMP/NOx for control infants over 6 to 65 days, corresponding to the time interval for data from iNO-treated infants. NOx values (Fig. 1A) ranged from 0.8 to $5.9 \mathrm{nmol} / \mu \mathrm{g}$ creatinine and increased slightly with postnatal age. cGMP values (Fig. 1B) ranged from 1.2 to $11.5 \mathrm{pmol} / \mu \mathrm{g}$ creatinine with a significant overall decline with postnatal age. The cGMP:NOx ratio (Fig. 1C), which may represent the overall efficiency of NOx signaling through soluble guanylate cyclase, ranged from 0.4 to $8.6 \mathrm{pmol} /$ nmol and values declined with increasing postnatal age $(p=0.0001)$.

\section{iNO-Treated Infants}

Infants in the TOLSURF studies were enrolled at a mean postnatal age of 9 days and received iNO at $20 \mathrm{ppm}$ for 2 to 4 days followed by 7 days each at doses of 10, 5, and 2 ppm. Sixty infants received doses of Infasurf and 65 received sham instillation. There were no significant differences in levels of urinary NOx or cGMP between treated and control groups; all analyses are accordingly presented for the entire cohort of TOLSURF infants. Urines were collected after enrollment but were not consistently obtained before beginning 
iNO. Data were obtained for 1,078 samples from 125 infants with an average of nine samples/infant and including 311 samples off iNO at 18 to 58 days after enrollment. Because of the short time on $20 \mathrm{ppm}$ iNO and the variability in timing of initial urine collections, reliable data for NOx and cGMP at this dose were obtained for only 19 infants; in this subpopulation there were no significant differences between levels of NOx, cGMP, and cGMP/NOx between 20 and $10 \mathrm{ppm}$ iNO. All data are, therefore, presented as mean values for 10-20, 5, 2, and 0 ppm dose iNO.

Fig. 2A shows the time course of NOx and cGMP in one infant, illustrating the declining concentrations as the iNO dose decreases from $20 \mathrm{ppm}$ and is stopped $(0 \mathrm{ppm}) 23$ days after enrollment. Summary results are shown in Fig. 2B along with mean values for the control infants. Values for NOx at all doses of iNO are statistically elevated compared with off iNO, and cGMP at 10 to $20 \mathrm{ppm}$ is significantly elevated compared with other doses and off iNO. The ratio of cGMP to NOx is lower at all iNO doses compared with both off iNO (average decrease of $38 \%, p<0.0001$ ) and untreated controls. NOx and cGMP levels for untreated control infants are lower than the 0 ppm values, but cGMP/NOx is similar. In Fig. 2C, mean NOx and cGMP values are plotted against the dose of iNO and indicate a nearly linear increase with maximal increases of 3.1- and 2-fold, respectively.

We tested for an association between NOx and cGMP levels and favorable pulmonary outcome near term, defined as survival without BPD at 36 and 40 weeks PMA, with results shown in Fig. 3. NOx levels are modestly higher in infants surviving without BPD at all concentrations of iNO with statistical significance reached at 2 ppm for 36 weeks (Fig. 3A) and both 2 ppm and off iNO for 40 weeks outcome (Fig. 3C). In addition, an analysis of NOx levels at $2 \mathrm{ppm}$ by quartile distribution indicated significantly higher proportion of infants without BPD at 40 weeks in the highest quartile (20/26, NOx range 6.2-15.8 nmol/ $\mu \mathrm{g}$ creatinine) compared with the lowest quartile (11/26, NOx range $0.9-3.2 \mathrm{nmol} / \mu \mathrm{g}$ creatinine, $p=0.02)$; these two groups of infants had similar gestational age $(25.5 \pm 1.1 \mathrm{vs}$. $25.0 \pm 1.1$, non-significant). By contrast, there were no significant differences by pulmonary outcome for levels of cGMP (Fig. 3B, D).

We next tested for relationships between NOx and cGMP and clinical factors known to influence pulmonary outcome: gender, gestational age, race, and severity of lung disease. Based on the results shown in Fig. 3, we focused these analyses on NOx and cGMP results at $2 \mathrm{ppm}$ iNO and off iNO. No gender differences were observed (data not shown). With increasing gestational age, there were trends for increasing NOx levels and decreasing cGMP and cGMP/NOx; a significant slope occurred only for cGMP at $0 \mathrm{ppm}$ iNO (slope $-0.66 \mathrm{pmol} / \mu \mathrm{g} / \mathrm{d}, p=0.04, r=0.19)$. Fig. 4 shows dose-response plots for iNO and NOx levels by race. NOx was higher for Caucasian infants than both Hispanic and African American infants off iNO and at each dose of inhaled gas. However, the increment in NOx level above baseline at each dose of iNO (e.g., NOx level at 2 ppm minus the $0 \mathrm{ppm}$ concentration) was similar for all three groups (not shown). There were no racial differences for levels of cGMP or cGMP/NOx (data not shown). In this cohort, survival without BPD was similar for Caucasian, African American, and Hispanic infants at both 36 weeks PMA $(33.3,36.6$, and $38.5 \%)$ and 40 weeks $(62.5,56.1$, and $61.5 \%)$, respectively. 
The mean RSS during the first 2 weeks after enrollment was used to assess severity of early lung disease. By regression analysis, both NOx and cGMP levels at 2 ppm iNO decreased significantly with increasing RSS (Fig. 5). There was no change in cGMP/NOx at 2 ppm iNO and negative slopes for NOx and cGMP versus RSS off iNO were not statistically significant (not shown).

\section{Discussion}

In this study, we demonstrate the utility of infant urine as a noninvasive source for measuring dose-dependent uptake of iNO and cGMP signaling in the lung. We found that urinary NOx levels are influenced by racial/ethnic background and severity of lung disease. These results are consistent with a role for both endogenous and inhaled NO, acting through soluble guanylate cyclase, in promoting lung growth and alveolization after premature birth.

Measurement of plasma or urinary NOx, in particular nitrate, has been explored in children and adults as a potential biomarker in a variety of clinical conditions. ${ }^{18-22}$ In normal adults, Kurioka et $\mathrm{al}^{23}$ found urinary NOx levels of 1.1 to $3.0 \mathrm{nmol} / \mathrm{\mu g}$ creatinine that were consistent day-to-day and independent of gender, age, and collection interval. For premature infants, mean urinary NOx concentrations of $6.1^{24}$ and $1.9^{25} \mathrm{nmol} / \mu \mathrm{g}$ creatinine are reported. The range of NOx concentrations in our control infants $(\sim 1-6 \mathrm{nmol} / \mu \mathrm{g}$ creatinine) is consistent with these previously reported values.

Short-term exposure to exogenous NO as a source of increased plasma nitrate is well documented in both adults ${ }^{26-28}$ and infants. ${ }^{12-14}$ To our knowledge, our results provide the first dose- and time-dependent data for urinary NOx after prolonged iNO administration. Notably, the fold increases in urinary NOx with iNO therapy are very similar to those for plasma in a similar premature infant population ${ }^{12}$ and in term infants, ${ }^{14}$ indicating that urinary NOx may be a reliable indicator of airway concentrations of iNO. We cannot rule out the possibility that anti-inflammatory effects of iNO, which have been observed in some lung injury studies, ${ }^{29,30}$ result in increased endogenous NO production that contributes to the increased plasma and urinary NOx.

In numerous tissues NO stimulates soluble guanylate cyclase, increasing levels of cGMP that activate target proteins involved in vasodilation and other responses. The level of urinary cGMP in our control infants is comparable to that reported for newborn infants ${ }^{31}$ and several fold higher than reported in adults. ${ }^{32,33}$ One earlier report found increased plasma cGMP after iNO treatment of adults with right heart failure, ${ }^{28}$ but there have been no descriptions of urinary cGMP for infants receiving iNO. We find that urinary cGMP levels increase with iNO administration, suggesting activation of soluble guanylate cyclase in lung epithelial and/or smooth muscle cells. Of interest, the cGMP/NOx ratio is lower on iNO versus off gas, suggesting decreased efficiency of exogenous $\mathrm{NO}$ in signaling that may reflect in part the limited diffusion distance of NO from air spaces. In the lung, NO is a mediator of VEGF action on angiogenesis that accompanies formation of new alveoli, ${ }^{34,35}$ and studies in transgenic mice support the involvement of cGMP in lung growth, particularly during hyperoxic lung injury. ${ }^{36}$ Our data support involvement of this pathway in infants. 
iNO therapy is currently widely used with benefit in both children and adults as treatment for pulmonary hypertension secondary to a variety of causes. More relevant to the current findings, iNO has been used in premature infants with persistent, severe chronic lung disease, and suspected pulmonary hypertension. ${ }^{37}$ iNO therapy for prevention of BPD has been beneficial in some clinical trials but not in others, ${ }^{2}$ which may reflect in part better response for African American infants. ${ }^{15,38,39}$ Our findings that urinary NOx levels are higher in Caucasian infants, and that there are no racial differences in cGMP levels, suggest that this trend in racial responsiveness is not due to differences in delivery or uptake of iNO or its signaling via cGMP.

We found that lower concentrations of urinary NOx were associated with more severe lung disease in infants on low (2 ppm) or off iNO. This relationship was observed for NOx and cGMP during the second postnatal month, with disease severity indicated by RSS, and at term for NOx with occurrence of BPD. Not unexpectedly, the mean RSS during weeks 2 to 5 was higher for infants who died or had BPD at 40 weeks PMA (4.8 \pm 1.9$)$ compared with infants who survived without BPD $(3.6 \pm 1.4, p=0.003)$. Somewhat surprisingly, cGMP concentrations were not related to pulmonary outcome at term. This could reflect greater variability and less change in cGMP than NOx values, precluding a significant association, or indicate an effect of NO independent of cGMP. In view of the animal data supporting the role of NO in alveogenesis, ${ }^{3-11}$ we speculate that lower NO production on a genetic and/or developmental basis (in lung and possibly other tissues) contributes to delayed alveogenesis and chronic lung disease in premature infants. Alternatively, lower NOx levels could result secondarily from more severe lung disease. Previously, improved pulmonary outcome was observed for iNO-treated infants with the lowest quartile of predose tracheal aspirate NOx, perhaps reflecting a deficiency of endogenous NO that was corrected by iNO therapy. ${ }^{12}$

There are some limitations to this study. While the control data establish the increase in NOx and cGMP observed in treated infants, the relatively small number of control infants is inadequate for analysis of NOx levels and pulmonary outcome. Because of the interval required for urine collection and variability in initiation of iNO therapy relative to sample collection, we could not reliably define the change in NOx and cGMP levels relative to preiNO in most infants. Due to study design of the trials, we did not collect plasma samples concurrent with urine samples and, thus, cannot provide paired comparisons of levels.

In summary, we report the first data for urinary NOx and cGMP in premature infants receiving iNO. We found that levels were independent of late surfactant treatment and increased in dose-dependent and parallel manner, which support, but do not establish, that effects of NO on lung development in the human are mediated via cGMP signaling. NOx concentrations are influenced by racial/ethnic background and by severity of initial lung disease, and infants who developed BPD or died had lower NOx levels at 1 to 2 months while receiving low levels of iNO and after discontinuing the gas. Reduced endogenous NO production may contribute to persistent lung disease that occurs in a subpopulation of premature infants with initial respiratory failure. Additional studies in infants not receiving iNO are underway to better define this relationship. 


\section{Acknowledgments}

This study supported by U01 HL094338 and UO1HL101798 Prematurity and Respiratory Outcome Program. We acknowledge the generous support from Ikaria, Inc., who provided nitric oxide and INOvent Delivery Systems for Tolsurf, and an unrestricted research grant, and ONY, Inc., (Edmund Egan) who provided Infasurf for Tolsurf. We thank Nancy Newton, Jeanette Asselin, Susan Kelley, and the other Research Coordinators for collection of clinical data and urine samples, Lisa Palermo for data management, Cheryl Chapin for laboratory supervision, Anne Marie Barrette and Anne Marie Gillespie for technical assistance, medical staff at all participating neonatal intensive care units for their involvement, and parents of TOLSURF infants for their participation.

\section{References}

1. Martínez-Ruiz A, Cadenas S, Lamas S. Nitric oxide signaling: classical, less classical, and nonclassical mechanisms. Free Radic Biol Med. 2011; 51(1):17-29. [PubMed: 21549190]

2. Cole FS, Alleyne C, Barks JD, et al. NIH Consensus Development Conference statement: inhaled nitric-oxide therapy for premature infants. Pediatrics. 2011; 127(2):363-369. [PubMed: 21220405]

3. Sherman TS, Chen Z, Yuhanna IS, Lau KS, Margraf LR, Shaul PW. Nitric oxide synthase isoform expression in the developing lung epithelium. Am J Physiol. 1999; 276(2 Pt 1):L383-L390. [PubMed: 9950902]

4. Munson DA, Grubb PH, Kerecman JD, et al. Pulmonary and systemic nitric oxide metabolites in a baboon model of neonatal chronic lung disease. Am J Respir Cell Mol Biol. 2005; 33(6):582-588. [PubMed: 16166742]

5. Shaul PW, Afshar S, Gibson LL, et al. Developmental changes in nitric oxide synthase isoform expression and nitric oxide production in fetal baboon lung. Am J Physiol Lung Cell Mol Physiol. 2002; 283(6):L1192-L1199. [PubMed: 12388364]

6. McCurnin DC, Pierce RA, Chang LY, et al. Inhaled NO improves early pulmonary function and modifies lung growth and elastin deposition in a baboon model of neonatal chronic lung disease. Am J Physiol Lung Cell Mol Physiol. 2005; 288(3):L450-L459. [PubMed: 15591412]

7. Tang JR, Markham NE, Lin YJ, et al. Inhaled nitric oxide attenuates pulmonary hypertension and improves lung growth in infant rats after neonatal treatment with a VEGF receptor inhibitor. Am J Physiol Lung Cell Mol Physiol. 2004; 287(2):L344-L351. [PubMed: 15064225]

8. Tourneux P, Markham N, Seedorf G, Balasubramaniam V, Abman SH. Inhaled nitric oxide improves lung structure and pulmonary hypertension in a model of bleomycin-induced bronchopulmonary dysplasia in neonatal rats. Am J Physiol Lung Cell Mol Physiol. 2009; 297(6):L1103-L1111. [PubMed: 19837849]

9. MacRitchie AN, Albertine KH, Sun J, et al. Reduced endothelial nitric oxide synthase in lungs of chronically ventilated preterm lambs. Am J Physiol Lung Cell Mol Physiol. 2001; 281(4):L1011L1020. [PubMed: 11557605]

10. Bland RD, Albertine KH, Pierce RA, Starcher BC, Carlton DP. Impaired alveolar development and abnormal lung elastin in preterm lambs with chronic lung injury: potential benefits of retinol treatment. Biol Neonate. 2003; 84(1):101-102. [PubMed: 12890945]

11. Bland RD, Albertine KH, Carlton DP, MacRitchie AJ. Inhaled nitric oxide effects on lung structure and function in chronically ventilated preterm lambs. Am J Respir Crit Care Med. 2005; 172(7): 899-906. [PubMed: 15976381]

12. Posencheg MA, Gow AJ, Truog WE, et al. NO CLD Investigators. Inhaled nitric oxide in premature infants: effect on tracheal aspirate and plasma nitric oxide metabolites. J Perinatol. 2010; 30(4):275-280. [PubMed: 19812581]

13. Aikio O, Metsola J, Vuolteenaho R, Perhomaa M, Hallman M. Transient defect in nitric oxide generation after rupture of fetal membranes and responsiveness to inhaled nitric oxide in very preterm infants with hypoxic respiratory failure. J Pediatr. 2012; 161(3):397-403, e1. [PubMed: 22554621]

14. Ibrahim YI, Ninnis JR, Hopper AO, et al. Inhaled nitric oxide therapy increases blood nitrite, nitrate, and s-nitrosohemoglobin concentrations in infants with pulmonary hypertension. J Pediatr. 2012; 160(2):245-251. [PubMed: 21907348] 
15. Ballard RA, Truog WE, Cnaan A, et al. NO CLD Study Group. Inhaled nitric oxide in preterm infants undergoing mechanical ventilation. N Engl J Med. 2006; 355(4):343-353. [PubMed: 16870913]

16. Keller RL, Merrill JD, Black DM, et al. Late administration of surfactant replacement therapy increases surfactant protein-B content: a randomized pilot study. Pediatr Res. 2012; 72(6):613619. [PubMed: 23037875]

17. Walsh MC, Wilson-Costello D, Zadell A, Newman N, Fanaroff A. Safety, reliability, and validity of a physiologic definition of bronchopulmonary dysplasia. J Perinatol. 2003; 23(6):451-456. [PubMed: 13679930]

18. Rångemark C, Wennmalm A. Smoke-derived nitric oxide and vascular prostacyclin are unable to counteract the platelet effect of increased thromboxane formation in healthy female smokers. Clin Physiol. 1996; 16(3):301-315. [PubMed: 8736716]

19. Cui R, Iso H, Pi J, et al. Metabolic syndrome and urinary cGMP excretion in general population. Atherosclerosis. 2007; 190(2):423-428. [PubMed: 16563400]

20. Koster-Kamphuis L, van Straaten EA, Kors WA, et al. Urinary NOx: creatinine ratios during gluten challenge in children with celiac disease. J Pediatr Gastroenterol Nutr. 2003; 36(3):372-375. [PubMed: 12604977]

21. Schiessl B, Strasburger C, Bidlingmaier M, et al. Plasma- and urine concentrations of nitrite/nitrate and cyclic Guanosinemonophosphate in intrauterine growth restricted and preeclamptic pregnancies. Arch Gynecol Obstet. 2006; 274(3):150-154. [PubMed: 16532320]

22. Baksu B, Davas I, Baksu A, Akyol A, Gulbaba G. Plasma nitric oxide, endothelin-1 and urinary nitric oxide and cyclic guanosine monophosphate levels in hypertensive pregnant women. Int $\mathbf{J}$ Gynaecol Obstet. 2005; 90(2):112-117. [PubMed: 16005006]

23. Kurioka S, Koshimura K, Sugitani M, Murakami Y, Nishiki M, Kato Y. Analysis of urinary nitric oxide metabolites in healthy subjects. Endocr J. 1999; 46(3):421-428. [PubMed: 10503995]

24. Tsukahara H, Takeuchi M, Hata I, et al. Assessment of endogenous nitric oxide formation in newborns: measurement of urinary nitrite and nitrate concentrations. Biol Neonate. 1997; 72(5): 322-326. [PubMed: 9395843]

25. Farkouh CR, Merrill JD, Ballard PL, Ballard RA, Ischiropoulos H, Lorch SA. Urinary metabolites of oxidative stress and nitric oxide in preterm and term infants. Biol Neonate. 2006; 90(4):233242. [PubMed: 16735789]

26. Wennmalm A, Benthin G, Edlund A, et al. Metabolism and excretion of nitric oxide in humans. An experimental and clinical study. Circ Res. 1993; 73(6):1121-1127. [PubMed: 8222083]

27. Mathru M, Huda R, Solanki DR, Hays S, Lang JD. Inhaled nitric oxide attenuates reperfusion inflammatory responses in humans. Anesthesiology. 2007; 106(2):275-282. [PubMed: 17264721]

28. Lukaszewicz AC, Mebazaa A, Callebert J, et al. Lack of alteration of endogenous nitric oxide pathway during prolonged nitric oxide inhalation in intensive care unit patients. Crit Care Med. 2005; 33(5):1008-1014. [PubMed: 15891329]

29. Bloomfield GL, Holloway S, Ridings PC, et al. Pretreatment with inhaled nitric oxide inhibits neutrophil migration and oxidative activity resulting in attenuated sepsis-induced acute lung injury. Crit Care Med. 1997; 25(4):584-593. [PubMed: 9142021]

30. Fioretto JR, Campos FJ, Ronchi CF, et al. Effects of inhaled nitric oxide on oxidative stress and histopathological and inflammatory lung injury in a saline-lavaged rabbit model of acute lung injury. Respir Care. 2012; 57(2):273-281. [PubMed: 21762562]

31. Manzke H, Spreter von Kreudenstein P, Dörner K, Kruse K. Quantitative measurements of the urinary excretion of creatinine, uric acid, hypoxanthine and xanthine, uracil, cyclic AMP, and cyclic GMP in healthy newborn infants. Eur J Pediatr. 1980; 133(2):157-161. [PubMed: 6244960]

32. Cui R, Iso H, Yamagishi K, et al. Relationship of urinary cGMP excretion with aging and menopausal status in a general population. J Atheroscler Thromb. 2009; 16(4):457-462. [PubMed: 19672035]

33. Bogdan M, Humbert M, Francoual J, et al. Urinary cGMP concentrations in severe primary pulmonary hypertension. Thorax. 1998; 53(12):1059-1062. [PubMed: 10195079] 
34. Le Cras TD, Markham NE, Tuder RM, Voelkel NF, Abman SH. Treatment of newborn rats with a VEGF receptor inhibitor causes pulmonary hypertension and abnormal lung structure. Am J Physiol Lung Cell Mol Physiol. 2002; 283(3):L555-L562. [PubMed: 12169575]

35. Leuwerke SM, Kaza AK, Tribble CG, Kron IL, Laubach VE. Inhibition of compensatory lung growth in endothelial nitric oxide synthase-deficient mice. Am J Physiol Lung Cell Mol Physiol. 2002; 282(6):L1272-L1278. [PubMed: 12003783]

36. Bachiller PR, Cornog KH, Kato R, Buys ES, Roberts JD Jr. Soluble guanylate cyclase modulates alveolarization in the newborn lung. Am J Physiol Lung Cell Mol Physiol. 2013; 305(8):L569L581. [PubMed: 23934926]

37. Banks BA, Seri I, Ischiropoulos H, Merrill J, Rychik J, Ballard RA. Changes in oxygenation with inhaled nitric oxide in severe bronchopulmonary dysplasia. Pediatrics. 1999; 103(3):610-618. [PubMed: 10049965]

38. Ballard RA. Inhaled nitric oxide in preterm infants—correction. N Engl J Med. 2007; 357(14): 1444-1445. [PubMed: 17914048]

39. Schreiber MD, Gin-Mestan K, Marks JD, Huo D, Lee G, Srisuparp P. Inhaled nitric oxide in premature infants with the respiratory distress syndrome. N Engl J Med. 2003; 349(22):20992107. [PubMed: 14645637] 

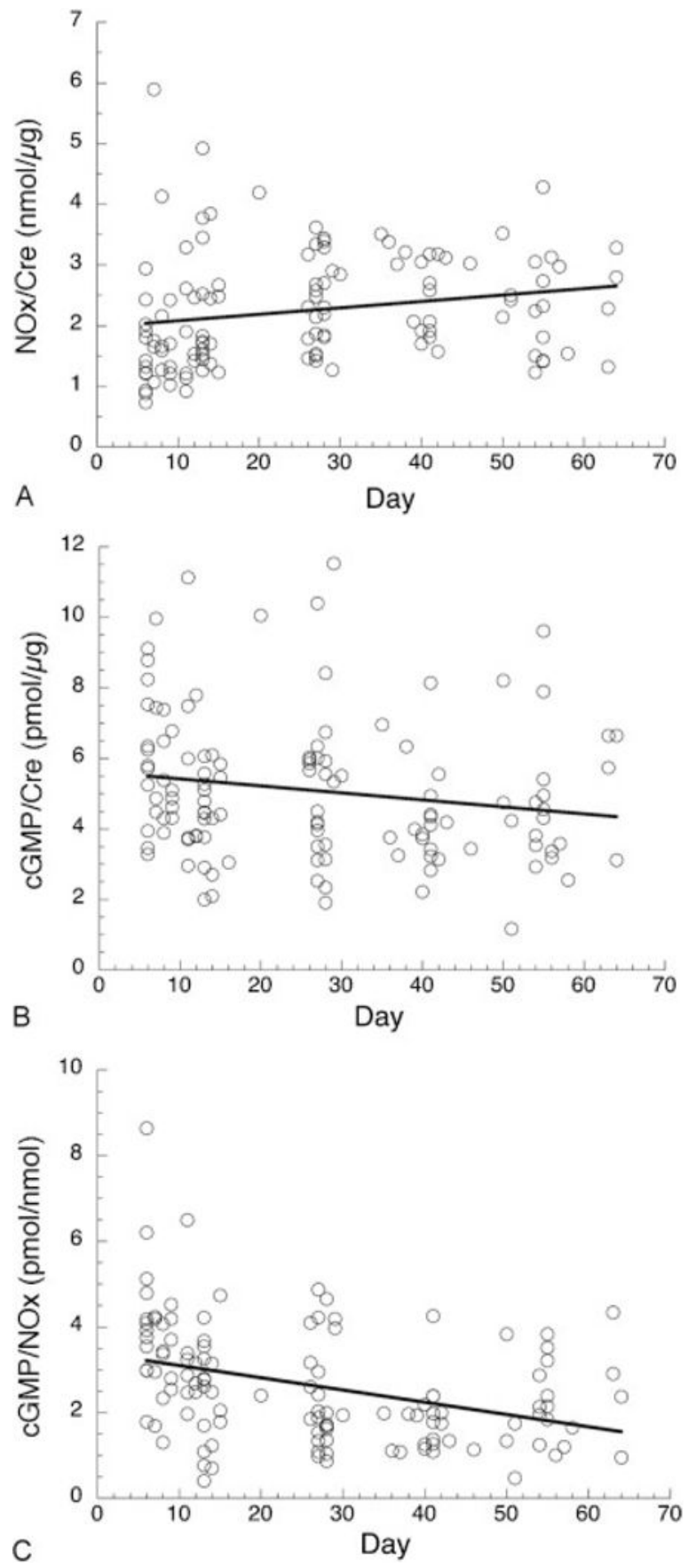

Fig. 1.

Time course for urinary nitric oxide metabolites (NOx) and cyclic guanosine monophosphate (cGMP) in control infants. (A) Regression analysis of NOx/creatinine. There is a slight increase between 6 and 65 days postnatal age (slope $=0.01 \mathrm{nmol} / \mu \mathrm{g} / \mathrm{d}, p=$ $0.03, r=0.20$ ); mean \pm standard deviation (SD), $2.25 \pm 0.92 \mathrm{nmol} / \mu \mathrm{g}$. (B) Regression analysis of cGMP/creatinine. Values decrease between 6 and 65 days postnatal age (slope $=$ $-0.02 \mathrm{pmol} / \mu \mathrm{g} / \mathrm{d}, p=0.05, r=-0.18)$; mean $\pm \mathrm{SD}, 5.1 \pm 2.0 \mathrm{pmol} / \mu \mathrm{g}$. (C) Regression analysis of cGMP/NOx. Values decrease with time (slope $=-0.03 \mathrm{nmol} / \mu \mathrm{g} / \mathrm{d}, p<0.0001, r=$ 
-0.37 ); mean $\pm \mathrm{SD}, 2.62 \pm 1.37 \mathrm{pmol} / \mathrm{nmol}$. Creatinine levels (not shown) did not change significantly with time (mean $\pm \mathrm{SD}, 17.6 \pm 7.1 \mathrm{mg} / \mathrm{dL}$ ). $N=120$ samples from 19 infants. 

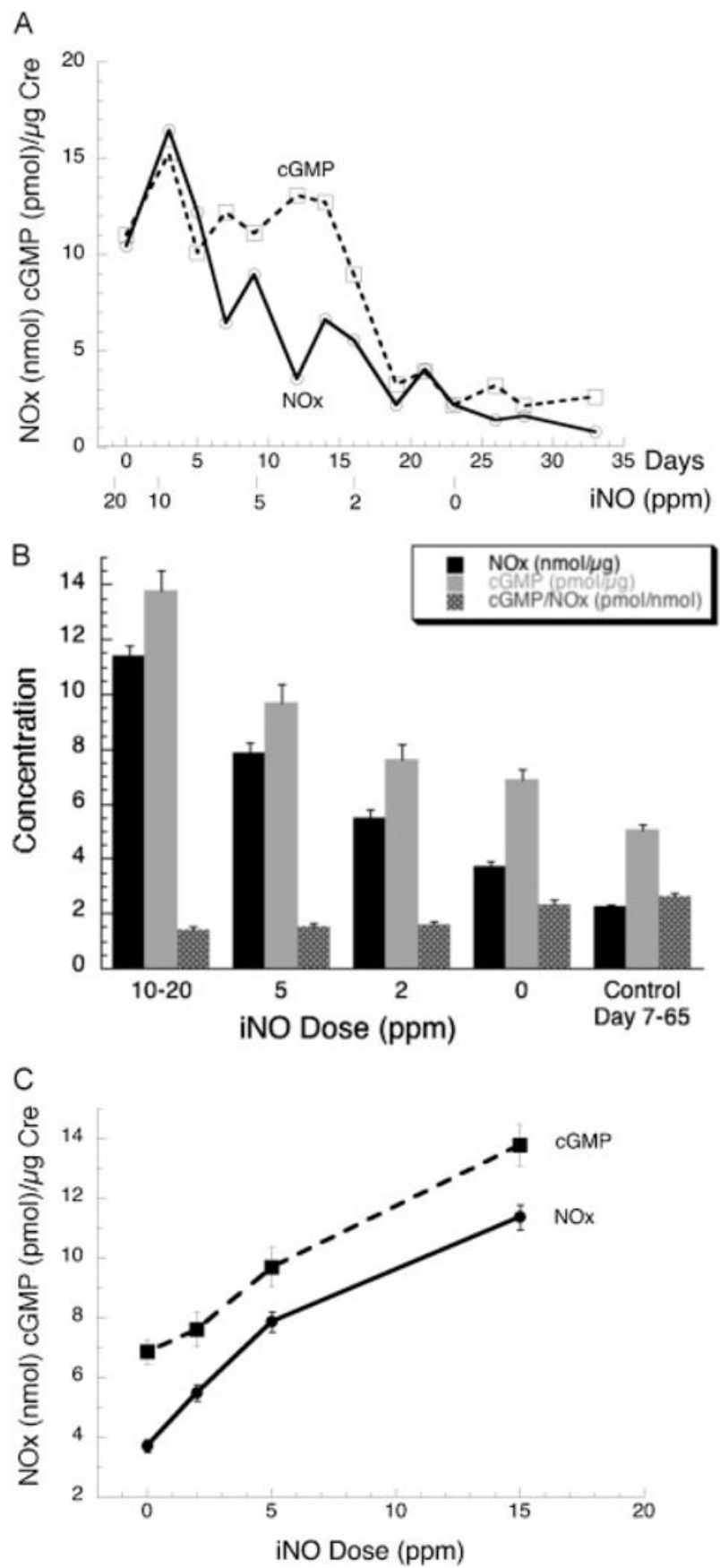

Fig. 2.

Time course for urinary nitric oxide metabolites (NOx) and cyclic guanosine monophosphate (cGMP) in inhaled nitric oxide (iNO)-treated infants. (A) Example of the time course for one infant by days in the study and iNO dose: 24 weeks' gestation, $640 \mathrm{~g}$ birth-weight infant who was enrolled on postnatal day 7. (B) Summary of levels by iNO dose. Data are mean \pm standard error (SE) for 2 to 5 values for 102 to 120 iNO-treated infants at each dose and mean \pm SE for 120 samples from 19 control infants over the same age range. For iNO-treated infants, all values for NOx are significantly different $(p<0.01)$ 
from each other, the cGMP level at 10 to $20 \mathrm{ppm}$ is greater than at other doses $(p<0.001)$, and cGMP/NOx off iNO is greater than at all iNO doses $(p<0.001)$. Creatinine levels (not shown) increased with postnatal age (mean $\pm \mathrm{SD}, 12.6 \pm 7.5$, slope $=0.13 \mathrm{mg} / \mathrm{dL} / \mathrm{d}, r=0.22$, $p<0.001$ ). (C) Regression plots of NOx and cGMP values by iNO dose. Parallel slopes are observed with maximal increase for NOx and cGMP of 3.1-fold and 2-fold, respectively; on linear regression, $p$ for slope is 0.02 for both parameters. Data from part (B). 

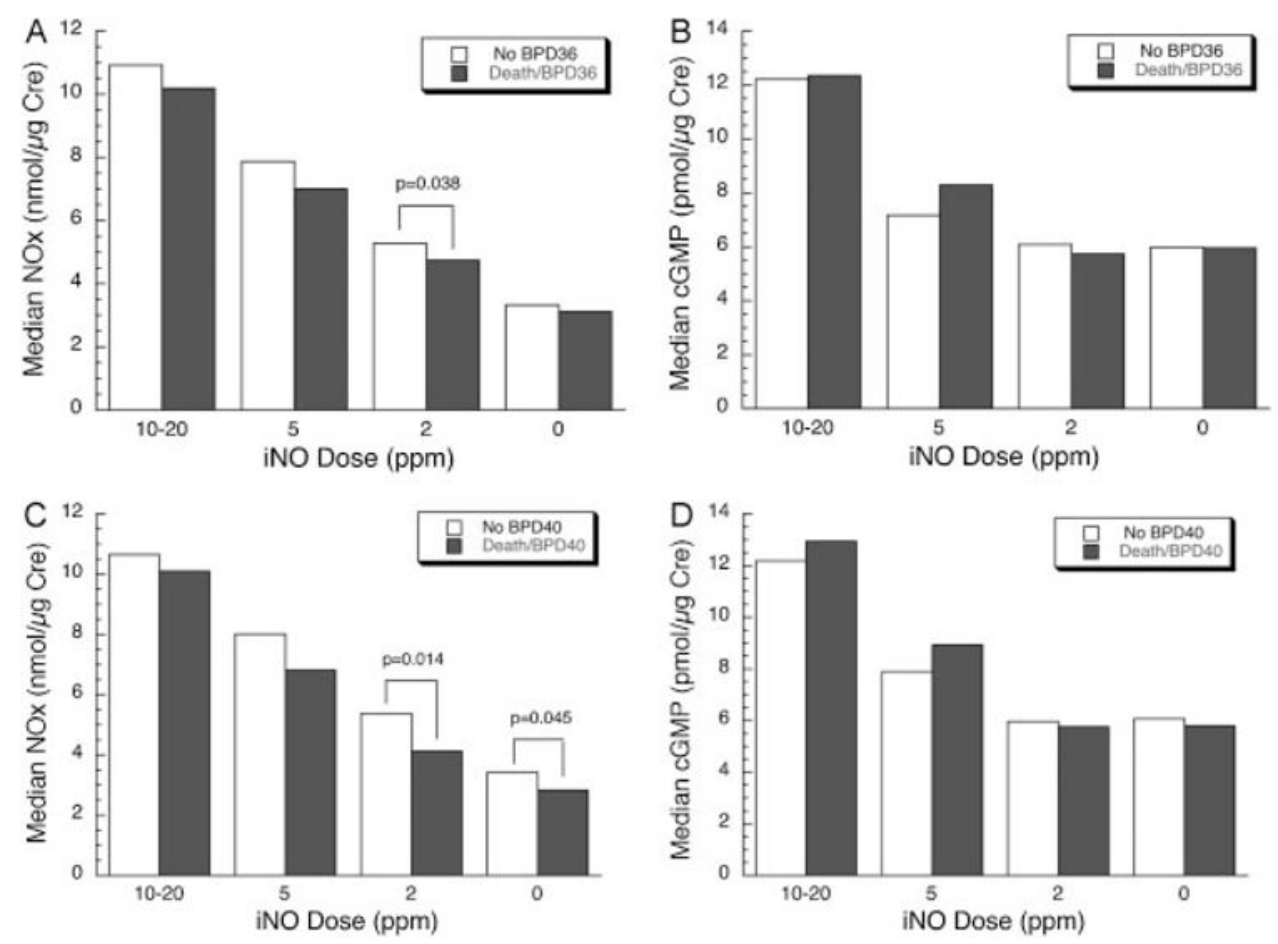

Fig. 3.

Nitric oxide metabolites (NOx) and cyclic guanosine monophosphate (cGMP) levels related to pulmonary outcome. (A) Urinary NOx at each inhaled nitric oxide (iNO) dose and diagnosis of moderate/severe bronchopulmonary dysplasia (BPD) at 36 weeks postmenstrual age (PMA). The median NOx level was significantly greater on 2 ppm iNO for infants surviving without BPD. (B) Urinary cGMP and BPD at 36 weeks PMA. There was no significant difference at any iNO dose. (C) Urinary NOx and BPD at 40 weeks PMA. The median NOx level was significantly higher on 2 ppm iNO and off iNO for infants surviving without BPD. (D) Urinary cGMP and BPD at 40 weeks PMA. There was no significant difference at any iNO dose. Data are median values; $n=42$ to 44 and 65 to 72 for no BPD and death/BPD at 36 weeks, respectively, and 65 to 72 and 41 to 47 for no BPD and death/BPD at 40 weeks, respectively. 


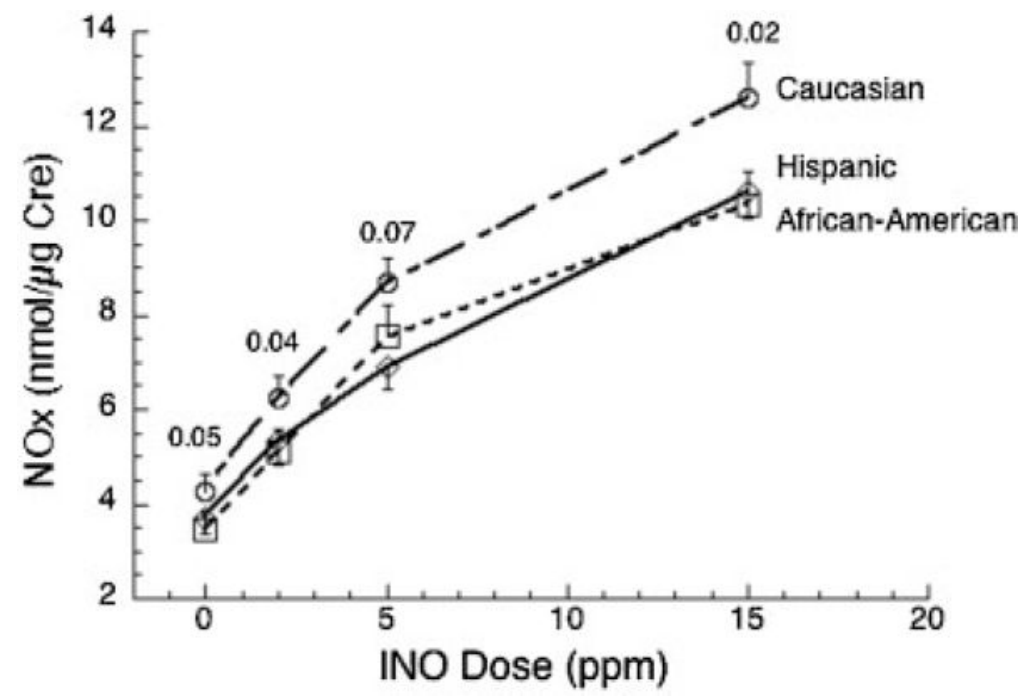

Fig. 4.

Nitric oxide metabolites (NOx) levels by maternal race/ethnicity. Concentrations are higher for Caucasian infants compared with African American and Hispanic infants at each inhaled nitric oxide (iNO) dose. There were no differences between groups for gestational age, birth weight, or respiratory severity score (RSS). Data are mean \pm SE with number of infants as shown in Table 1; $p$ values are indicated for Caucasian infants versus all other infants. 

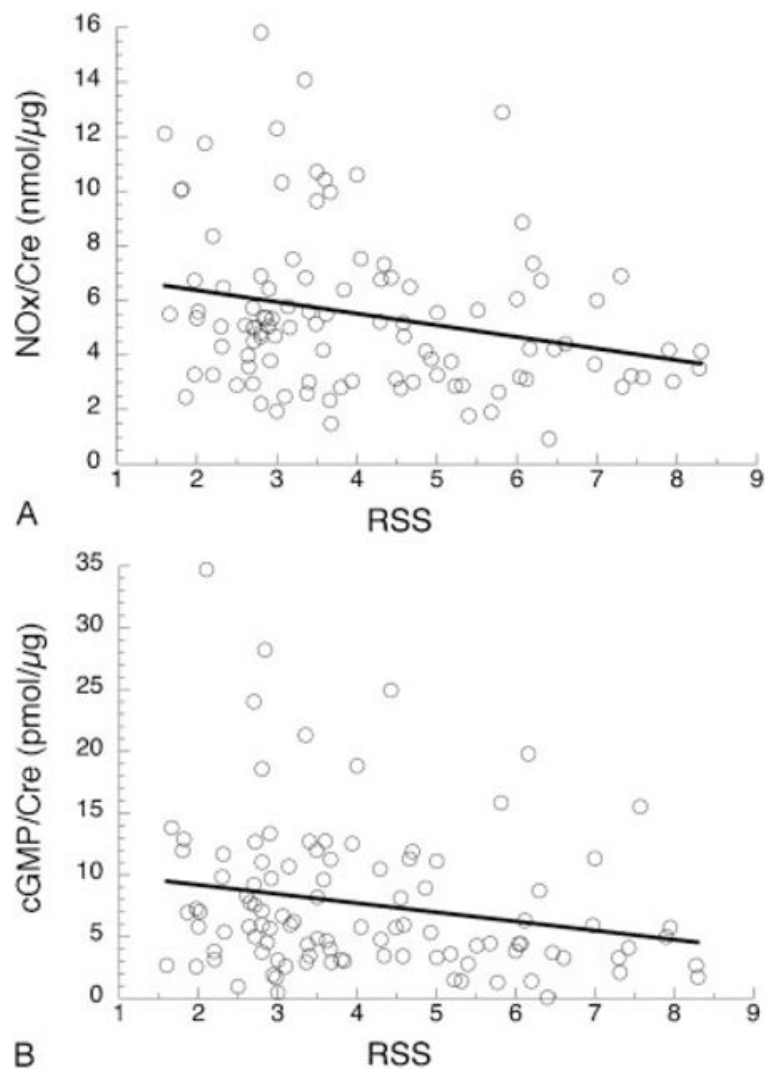

Fig. 5.

Respiratory severity score (RSS) and levels of nitric oxide metabolites (NOx) and cyclic guanosine monophosphate (cGMP). (A) NOx concentrations on inhaled nitric oxide (iNO) dose of $2 \mathrm{ppm}$. By regression analysis, NOx decreases with increasing mean RSS; slope = $-0.43, p=0.01, r=0.25$ for 104 infants. (B) cGMP concentrations on iNO dose of $2 \mathrm{ppm}$. cGMP levels decrease with increasing RSS; slope $=-0.70, p=0.05, r=0.20$ for 113 infants. RSS is mean of 3 to 5 daily values during the dosing period (7-14 days). 


\section{Table 1}

\section{Demographics of study groups}

\begin{tabular}{|l|l|l|l|}
\hline & iNO treated & Control & $p$ \\
\hline$n$ & 125 & 19 & \\
\hline Gestational age (wk) & $25.3 \pm 1.1$ & $25.7 \pm 1.2$ & NS \\
\hline Birth weight (g) & $733 \pm 168$ & $833 \pm 207$ & 0.04 \\
\hline Gender (male/female) & $71 / 54$ & $12 / 7$ & NS \\
\hline Race (caus/aa/his/other) & $48 / 41 / 26 / 9$ & $4 / 8 / 7 / 0$ & NS \\
\hline Multiples & $24(19.2 \%)$ & $2(10.6 \%)$ & NS \\
\hline Initial RSS & $4.1 \pm 1.7$ & $2.0 \pm 1.8$ & $<0.001$ \\
\hline Survive without BPD at $36 \mathrm{wk}$ & $46(36.8 \%)$ & $12(63.2 \%)$ & 0.04 \\
\hline Survive without BPD at $40 \mathrm{wk}$ & $79(63.2 \%)$ & $14(73.7 \%)$ & NS \\
\hline
\end{tabular}

Abbreviations: aa, African American; BPD, bronchopulmonary dysplasia; caus, Caucasian; his, Hispanic; iNO, inhaled nitric oxide; RSS, respiratory severity score. 